\title{
Hofmeister Effects in Enzymatic Activity: Weak and Strong Electrolyte Influences on the Activity of Candida rugosa Lipase
}

\author{
Andrea Salis,* Dagmar Bilaničová, Barry W. Ninham, ${ }^{\dagger}$ and Maura Monduzzi* \\ Dipartimento di Scienze Chimiche, Università di Cagliari-CSGI Cittadella Monserrato, S.S. 554 Bivio Sestu, \\ 09042 Monserrato, Italy
}

Received: September 27, 2006; In Final Form: November 17, 2006

\begin{abstract}
The effects of weak and strong electrolytes on the enzymatic activity of Candida rugosa lipase are explored. Weak electrolytes, used as buffers, set the $\mathrm{pH}$, while strong electrolytes regulate the ionic strength. The interplay between $\mathrm{pH}$ and ionic strength has been assumed to be the determinant of enzymatic activity. In experiments that probe activities by varying these parameters, there has been little attention focused on the role of specific electrolyte effects. Here we show that both buffers and the choice of background electrolyte ion strongly affect the enzymatic activity of Candida rugosa lipase. The effects here shown are dramatic at high salt concentration; indeed, a $2 \mathrm{M}$ concentration of $\mathrm{NaSCN}$ is able to fully inactivate the lipase. By contrast, $\mathrm{Na}_{2}-$ $\mathrm{SO}_{4}$ acts generally as an activator, whereas $\mathrm{NaCl}$ shows a quasi-neutral behavior. Such specific ion effects are well-known and are classified among the "Hofmeister effects". However, there has been little awareness of them, or of their potential for optimization of activities in the enzyme community. Rather than the effects per se, the focus here is on their origin. New insights into mechanism are proposed.
\end{abstract}

\section{Introduction}

1.1. Background. It is a trite observation that electrolytes are integral components of biological systems. Inter alia, they are involved in several enzymatic pathways essential to life. However, the role of electrolytes in determining mechanisms of enzymatic action is at best only partially understood.

That situation, the nature and origin of specific ions, or Hofmeister effects, is universal in physical chemistry generally. ${ }^{1}$

In elementary physical chemistry a distinction is made between two kinds of electrolytes. In the first approximation, strong electrolytes are fully dissociated in water. Weak electrolytes are only partially dissociated in water. The distinction then assigns to weak electrolytes a very important role since they modify acid/base equilibria of water solutions. The simultaneous presence of an electrolyte in both its undissociated and dissociated forms in water solution gives rise to a $\mathrm{pH}$ buffer. The equilibrium between the two forms opposes $\mathrm{pH}$ variations caused by the addition of strong acids or bases to the system. Strong (fully dissociated) electrolytes are believed to have little effect on $\mathrm{pH}$. This is partially true only at low ionic strength. ${ }^{2,3}$

Enzymes, as for all proteins, contain a large number of acid and basic groups located mainly on the exterior "surface". When an enzyme is placed in aqueous media, the superficial net charge of the enzyme can change as a result of bulk $\mathrm{pH}$ modifications that affect the acid/basic dissociation equilibria. Consequently, enzymatic activity, structural features and solvation, can change radically. Changes in bulk $\mathrm{pH}$ may affect charge distribution on the substrate and product also. In effect, charge variations at the interfacial enzymatic "surface" will be reflected in changes in the binding of the substrate, and the catalytic efficiency. It is a commonly held opinion that the effect of $\mathrm{pH}$ on the rate of

* Corresponding authors. Telephone: +39 070 6764362/4385. Fax: +39 0706754388. E-mail: asalis@unica.it (A.S.); monduzzi@unica.it (M.M.)

$\dagger$ Department of Applied Mathematics, ANU, Canberra, Australia. Visiting Professor at Universities of Cagliari and Florence (Italy). an enzymatic reaction can be explained by assuming that only one charged enzymatic form gives rise to the optimal catalytic performance. In other words, there is an optimum $\mathrm{pH}$ value that favors the maximum concentration of the enzyme-substrate intermediate.

Ionic strength is another variable parameter that may affect catalytic activity. At high ionic strength a lowering of the carboxylic acid $\mathrm{p} K_{\mathrm{a}}$ 's may occur, but at neutral $\mathrm{pH}$ little effect on the overall charge of the enzyme molecule is generally observed, unless the variation in charge occurs within the active site.

In the past decade it has become clear that such first-order theoretical notions are too crude to characterize real enzyme performance. Although ionic strength and $\mathrm{pH}$ are recognized as important factors that affect enzyme activity, specific ion effects are not embraced by classical (electrostatic) theories of physical chemistry. Indeed, enzyme conformations, stability, and activity are a result of a complex interplay of factors. These are usually subsumed under separate competing terms such as electrostatic, dipolar, and van der Waals interactions, hydrogen bonds, solvation and polarization effects, and associationdissociation equilibria of charged groups.

The effects of different neutral salts on the solubility of proteins were first reported in a systematic way by Franz Hofmeister in $1888 .{ }^{4}$ His historical papers have been recently translated into English and republished. ${ }^{5}$ For proteins, the precipitation (salting-out)/solubilization (salting-in) efficiency of the anions, at a fixed ionic strength, was found to decrease/ increase in the following order:

$$
\begin{aligned}
\mathrm{H}_{2} \mathrm{PO}_{4}^{-}>\mathrm{SO}_{4}{ }^{2-}>\mathrm{F}^{-}>\mathrm{Cl}^{-}>\mathrm{Br}^{-}>\mathrm{NO}_{3}^{-}>\mathrm{I}^{-}> \\
\mathrm{ClO}_{4}^{-}>\mathrm{SCN}^{-}
\end{aligned}
$$

The phenomenon embraced by this sequence is referred as the Hofmeister series (HS). Moreover, the salting-out efficiency was 
found in the $\mathrm{HS}$ order when the $\mathrm{pH}$ is higher than the isoelectric point $(\mathrm{p} I)$ and in the opposite order at $\mathrm{pH}<\mathrm{p} I .^{6-10}$

Enzymatic activity also seems to follow the HS as reported in several works from 1960 to the present time. ${ }^{11-23}$ Sometimes the specific activating/deactivating effect of ions was recognized as a Hofmeister effect. Sometimes, it was attributed to other factors. ${ }^{24}$

These effects are well-known by biochemists. Nevertheless, the development of a theoretical framework that allows a description of the ion-specific interplay between ionic strength, activity coefficients, $\mathrm{pH}$, and enzyme activity has received little attention.

"Specific ion" effects occur not just in biochemistry, but almost everywhere in physical, colloid, polymer, and surface chemistry. ${ }^{1,25-31}$ Until recently, they have remained inexplicable with conventional theories of solution and colloid chemistry. However, some progress is now under way. ${ }^{1}$

1.2. Theoretical Ambiguities. A first attempt to account for Hofmeister phenomena assigns the matter to changes in bulk water structure, induced by ions (ionic hydration). ${ }^{32-35}$ The ion specificity is determined by the ability of ions to form (kosmotropic) or to break (chaotropic) hydrogen bonds in water systems. ${ }^{33-36}$ A more recent approach takes into account the fact that the nonelectrostatic forces experienced by ions near an interface must be treated at the same level as those forces due to the classical electrostatic potential. ${ }^{37}$ These nonelectrostatic, electrodynamic fluctuation (called for brevity "dispersion" or "NES") forces are treated only in linear approximation in the standard framework and are omitted in the classical DLVO, Onsager, Debye-Hückel, and Born types of electrostatic theories. ${ }^{38-40}$ By contrast, electrostatic effects are treated in a nonlinear theory. The result is that specific ion effects are missing or underestimated. The neglect of the quantum mechanical fluctuation forces, rather their too crude approximation via linear theories of quantum electrodynamics in interactions, is not limited to specific surface adsorption of ions. The same effects accessible via bulk dielectric susceptibilities affect and change (Born) free energies and hydration. ${ }^{41-43}$ The theory also deals with overlap of hydration shells which affect the ion specificity of activity coefficients. The two approaches are equivalent, ${ }^{32-35}$ the only difference being that the second is somewhat better quantified (see discussion in ref 9).

Hydrated ion-ion solvent mediated interactions or hydrated ion-surface interactions, which are the heart of the Hofmeister issue, involves, more or less, overlap of hydration shells. This leads to the concept of "hard" and "soft" ions. Although the second approach ${ }^{38}$ has focused on the specificity of surfaceion interactions reflected in a proper treatment of dispersion forces, these nonelectrostatic (NES) ionic and solvent frequencydependent dielectric susceptibilities (as exemplified by excess polarizabilities) play a role in both characterizations. The (self) interaction of a bare ion with water in the presence of its neighbors and/or an ion with an interface via NES interactions ${ }^{41,43}$ gives rise to strong or weak hydration and the labeling of ions as kosmotropic or chaotropic. These hydrated or "dressed" ions then experience further specific NES dispersion potentials directly with an interface, and with its profile of hydration. The two apparently different approaches are consistent, and the second in fact includes the first. This fact renders the arguments between advocates who attribute experimental results to one approach (bulk effects), as opposed to the other (surface effects), an empty debate. Both bulk and surface effects play a role. ${ }^{2,9}$ Changes in the Hofmeister series above and below the $\mathrm{p} I$ of proteins, ${ }^{9}$ and with $\mathrm{pH}$ measurements with cacodylate/ phosphate or interchange of $\mathrm{Na}^{+}$and $\mathrm{K}^{+}, 2$ are unambiguous evidence that surface effects in those particular cases play a determining role.

Moreover, it has been recently shown that ions affect the first few hydration shells. Ions neither enhance nor weaken the hydrogen bond network, at least over the time scale experienced by femtosecond pump spectroscopy. ${ }^{44,45}$ Thus Hofmeister effects are likely to find an explanation in interactions of the ions with the macromolecule and its first hydration shell. ${ }^{46}$

1.3. Present Work. For the complicated environments that concern us, both biomolecules and electrolytes are present simultaneously. It usually holds, at least in textbooks, that whatever the weak electrolyte that constitutes the buffer, the same biochemical result will be obtained. There is some awareness by biochemists of possible deviations from this expectation. ${ }^{47}$ We will show from the present work that this is not true, as also for a previous study. ${ }^{18}$ It is also known, but not yet rationalized, that at the same concentration the choice of the neutral electrolyte ion pair changes enzyme activities. ${ }^{15,19,20}$

Specifically, the present work deals with the effect of buffers (weak electrolytes) and neutral salts (strong electrolytes) on the hydrolytic activity of the lipase (E.C. 3.1.1.3) from Candida rugosa.

We will show the following:

i. The function of the buffer is not only to regulate $\mathrm{pH}$. The nature of the buffer anion/cation affects the enzyme activity/ $\mathrm{pH}$ behavior.

ii. Increasing the buffer concentration leads to a maximum in the activity/pH curves obtained with the different buffers. However, the maximum activity still depends on the type of buffer.

iii. Enzyme activity is ion specific. In particular, an ion with low excess polarizability $\left(\mathrm{SO}_{4}{ }^{2-}\right)$ is activating; a Hofmeister series (HS) neutral anion $\left(\mathrm{Cl}^{-}\right)$has a small activating/deactivating effect; an ion with high excess polarizability $\left(\mathrm{SCN}^{-}\right)$is strongly deactivating.

iv. These Hofmeister effects on enzymatic activity are modulated by both the type and concentration of the buffer.

The results presented are interpreted on the basis of developing new theoretical notions. ${ }^{38}$

\section{Materials and Methods}

2.1. Chemicals. Lipase from Candida rugosa (lipase AY) was obtained from Amano Enzyme (Japan). Sodium dihydrogen orthophosphate, $99 \%$, and disodium hydrogen orthophosphate, 99\%, were purchased from Carlo Erba. Sodium hydroxide, 99\%, and sodium thiocyanate, 99\%, were from Sigma. Sodium chloride, $99.5 \%$, was from Merck. Sodium citrate, 99\%, was from Aldrich. Citric acid, $>99.5 \%, p$-nitrophenyl acetate, $99 \%$ ( $p$-NPA), $p$-nitrophenol, $>99.5 \%$ ( $p$-NP-OH), and 2-propanol, $99.8 \%$, were from Fluka. Tris(hydroxymethyl)aminomethane (Tris $\cdot \mathrm{HCl}$ buffer) was from Bio-Rad. Glass electrode calibration buffer solutions, $\mathrm{pH} 4$ (citric acid/sodium hydroxide/hydrogen chloride), and $\mathrm{pH} 7$ (disodium hydrogen phosphate/potassium dihydrogen phosphate), both traceable to SRM from NIST and PTB, were from Merck.

2.2. Preparations of the Buffer and Buffer/Salt Solutions. Both concentrations (5 and $200 \mathrm{mM}$ ) of sodium phosphate, sodium citrate, and Tris $\cdot \mathrm{HCl}$ buffers were prepared at various $\mathrm{pH}$ values. Buffer/salt solutions were prepared by dissolving pure salts into the buffer solution at initial $\mathrm{pH} 7.00$ and brought to the appropriate volume. Distilled water, purified through a 

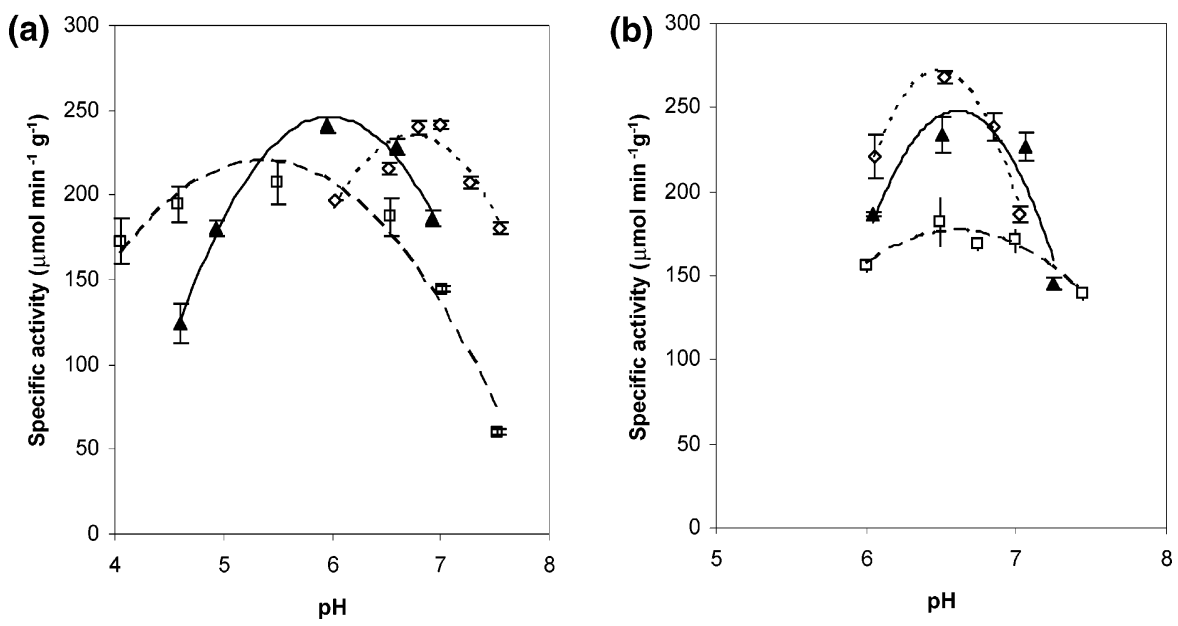

Figure 1. Enzymatic activity of Candida rugosa lipase versus pH with different 5 (a) and $200 \mathrm{mM}$ (b) buffers: (ム) sodium citrate; ( $\diamond)$ sodium phosphate; ( $\square$ ) Tris $\bullet \mathrm{HCl}$.

Millipore system (Simplicity 185) and with conductivity $<0.054$ $\mu \mathrm{S} \mathrm{cm}^{-1}$, was used.

2.3. pH Measurements. The $\mathrm{pH}$ measurements of a series of aqueous buffer and buffer/salt solutions were performed by using a $\mathrm{pH}$ meter $\mathrm{pH}-526$, WTW, equipped with a $\mathrm{pH}$ glass electrode SenTix81 (range of linearity $\mathrm{pH} 2-10$; typical reliable reproducibility of measurements up to electrolyte concentration $2 \mathrm{M})$. The glass electrode was calibrated, using a two point calibration procedure and standard buffer solutions (with nominal $\mathrm{pH}$ of 4.00 and 7.00 or 7.00 and 10.00 depending on measured or expected $\mathrm{pH}$ of prepared solution), before starting $\mathrm{pH}$ measurements of each series of solutions with increasing salt concentration.

The solution under investigation was stirred for $2 \mathrm{~min}$ and allowed to rest for $1 \mathrm{~min}$ before the $\mathrm{pH}$ value was recorded. For each solution the $\mathrm{pH}$ measurements were repeated at least five times. All measurements were made at $25{ }^{\circ} \mathrm{C}$ using a thermostated bath and at atmospheric pressure.

2.4. Lipase Assay. The lipase-catalyzed hydrolysis of $p$ nitrophenylacetate to $p$-nitrophenol was used to determine the enzymatic activity. ${ }^{20}$ A typical experiment was performed by using $200 \mu \mathrm{L}$ of a $50 \mathrm{mM} p$-NPA solution in 2-propanol that was mixed with $1.6 \mathrm{~mL}$ of buffer solution (5 and $200 \mathrm{mM}$ ) with or without salt. The reaction was started by adding 200 $\mu \mathrm{L}$ of $7.5 \mathrm{mg} / \mathrm{mL}$ crude lipase solution.

Spectrophotometric measurements were carried out after a determination of calibration lines of $p$-nitrophenol absorbance vs concentration, at all $\mathrm{pH}$ values, and for all salt types and concentrations. Each calibration line gave a different angular coefficient that, for the Lambert-Beer law, is proportional to the molar absorptivity coefficient $(\epsilon)$ at a determined wavelength. Each calibration was performed by reading the absorbance at $400 \mathrm{~nm}$, using a Cary $50 \mathrm{UV}$-visible spectrophotometer, of several $p$-nitrophenol ( $p$-NP-OH) standards dissolved in the buffer solution at the given sodium salt concentration. Correlation coefficients in the range 0.996-0.999 were determined. The $\epsilon$ values obtained can be defined as "observed" molar absorptivity coefficients $\left(\epsilon_{\mathrm{obs}}\right)$, since they are determined by the equilibrium shown in Scheme 1.

The $\epsilon_{\mathrm{obs}}$ is the result of contributions to the measured $\epsilon$ of the two absorbing species, $p$-nitrophenol and $p$-nitrophenolate $\left(p-\mathrm{NP}^{-} \mathrm{O}^{-}\right)$at $\lambda=400 \mathrm{~nm}\left(\epsilon_{p-\mathrm{NP}-\mathrm{O}^{-}} \gg \epsilon_{p-\mathrm{NP}-\mathrm{OH}}\right)$. It should be remarked that in these calibrations all the absorbing species involved in the reaction together with buffers and added salts were considered.
SCHEME 1: Acid/Base Equilibrium between $p$-Nitrophenol and $p$-Nitrophenolate $\left(p K_{\mathrm{a}}=7.15\right)$<smiles>O=Cc1cc([O-])ccc1[N+](=O)[O-]</smiles>

Spontaneous hydrolysis of $p$-NPA may also occur; this was experimentally quantified and enzymatic activity data were corrected by taking into account this phenomenon. One unit of hydrolytic activity is defined as the amount of enzyme that releases $1 \mu \mathrm{mol}$ of $p$-NP-OH per minute.

All measurements were repeated from three to five times. Standard deviations, as error bars, are reported in Figures 1, 2, and 4 .

\section{Results}

Figure 1a reports the curves of Candida rugosa lipase activity as a function of $\mathrm{pH}$ obtained with three different buffers (at 5 $\mathrm{mM})$, namely sodium citrate, sodium phosphate, and Tris $\cdot \mathrm{HCl}$. The main result is that the activity depends on both the $\mathrm{pH}$ and the specific weak electrolyte used to prepare the buffer. From this fact two other points arise:

i. The $\mathrm{pH}$ of maximum activity varies with the buffer. It is about 5.4 for Tris $\cdot \mathrm{HCl}, 6$ for citrate, and 6.7 for phosphate;

ii. The maximum activity of Candida rugosa lipase has different values for each buffer, i.e., phosphate $\approx$ citrate $>$ Tris $\bullet$ $\mathrm{HCl}$.

The experiments were then performed by using more concentrated buffers $(200 \mathrm{mM})$. The results are reported in Figure 1b. Compared with the previous situation, the curve maxima are closer, falling in a very narrow $\mathrm{pH}$ range (6.56.6). Moreover, the enzymatic activity decreases significantly in the order phosphate $>$ citrate $>$ Tris $\cdot \mathrm{HCl}$.

These results are likely to hold specifically for Candida rugosa lipase only. Indeed, similar measurements performed in $5 \mathrm{mM}$ buffers using the lipase from Aspergillus niger showed a slight specific dependence on the buffer anion/cation. However, unlike the results above, the highest activity was observed with Tris $\cdot \mathrm{HCl}$ buffer, as reported in Figure 2. This is a strong indication that adsorption of buffer ions at substrate and enzyme is involved.

The activity of the Candida rugosa lipase, in the presence of both weak and strong electrolytes, was then assayed. Different 


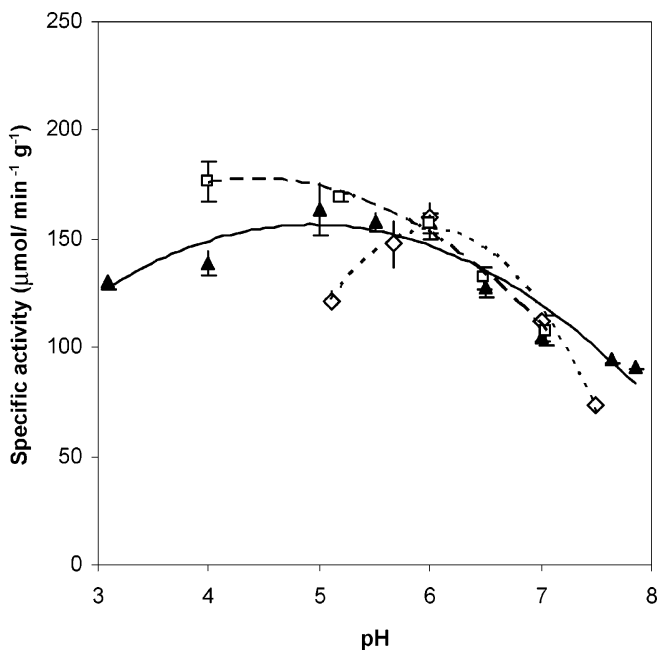

Figure 2. Enzymatic activity of Aspergillus niger lipase versus $\mathrm{pH}$ with different $5 \mathrm{mM}$ buffers: $(\mathbf{\Lambda})$ sodium citrate; $(\diamond)$ sodium phosphate; ( $\square)$ Tris $\cdot \mathrm{HCl}$

salts (concentrations 0.5 and $1 \mathrm{M} \mathrm{Na}_{2} \mathrm{SO}_{4}, 0.5,1$, and $2 \mathrm{M} \mathrm{NaCl}$ and $\mathrm{NaSCN}$ ) together with the substrate $p$-nitrophenyl acetate were dissolved in different buffer solutions, namely phosphate and Tris $\cdot \mathrm{HCl}(5$ and $200 \mathrm{mM}$ ), at the initial $\mathrm{pH}$ 7. If we use the standard nomenclature of the Hofmeister series, $\mathrm{Na}_{2} \mathrm{SO}_{4}$ is considered to be kosmotropic, $\mathrm{NaCl}$ is neutral, and $\mathrm{NaSCN}$ is chaotropic. Prior to each enzymatic activity determination, $\mathrm{pH}$ measurements were performed by means of a glass electrode. The results are reported in Figure 3. As expected, both concentration and type of buffer affect measured $\mathrm{pH}$ values at a quantitative and qualitative level.

The substrate solutions in the presence of both buffers and salts were then used for the determination of the enzymatic activity. The determination with $2 \mathrm{M} \mathrm{Na}_{2} \mathrm{SO}_{4}$ is not reported since the solution was turbid and thus not suitable for spectrophotometric determinations. Results are reported in Figure 4. In all cases the three salts act in a similar way; in particular, the sulfate is generally activating, chloride is neutral or slightly activating/deactivating, and thiocyanate is strongly deactivating. Only in the presence of $5 \mathrm{mM}$ Tris $\cdot \mathrm{HCl}$ (Figure 4c) is the sulfate slightly deactivating.

\section{Discussion}

4.1. Problems with Ion Specificity. Ion-specific effects on enzymatic activity have been a matter of debate for more than 40 years. ${ }^{11,12}$ Theoretical models are not predictive, even at a qualitative level. The problem is complicated by the superposition of several different effects, which are difficult to disentangle. The purpose of this discussion is first to elicit where the problems lie. Once identified, these will be discussed separately. Then we try to rationalize them at a qualitative level, taking into account contributions from dispersion forces. The issues are the following:

i. Both $\mathrm{pH}$ and salt addition affect enzyme activity. These effects are usually treated separately via simple kinetic models (section 4.2), the second being discussed only in terms of ionic strength variations. No ion specificity is usually taken into account. A recent work explained Hofmeister effects with the bulk $\mathrm{pH}$ variations induced by the salt addition. ${ }^{48}$ This cannot be done at high salt concentration, as shown recently by two works concerning the enzymatic activities of Aspergillus niger lipase $^{20}$ and horseradish peroxidase. ${ }^{21}$
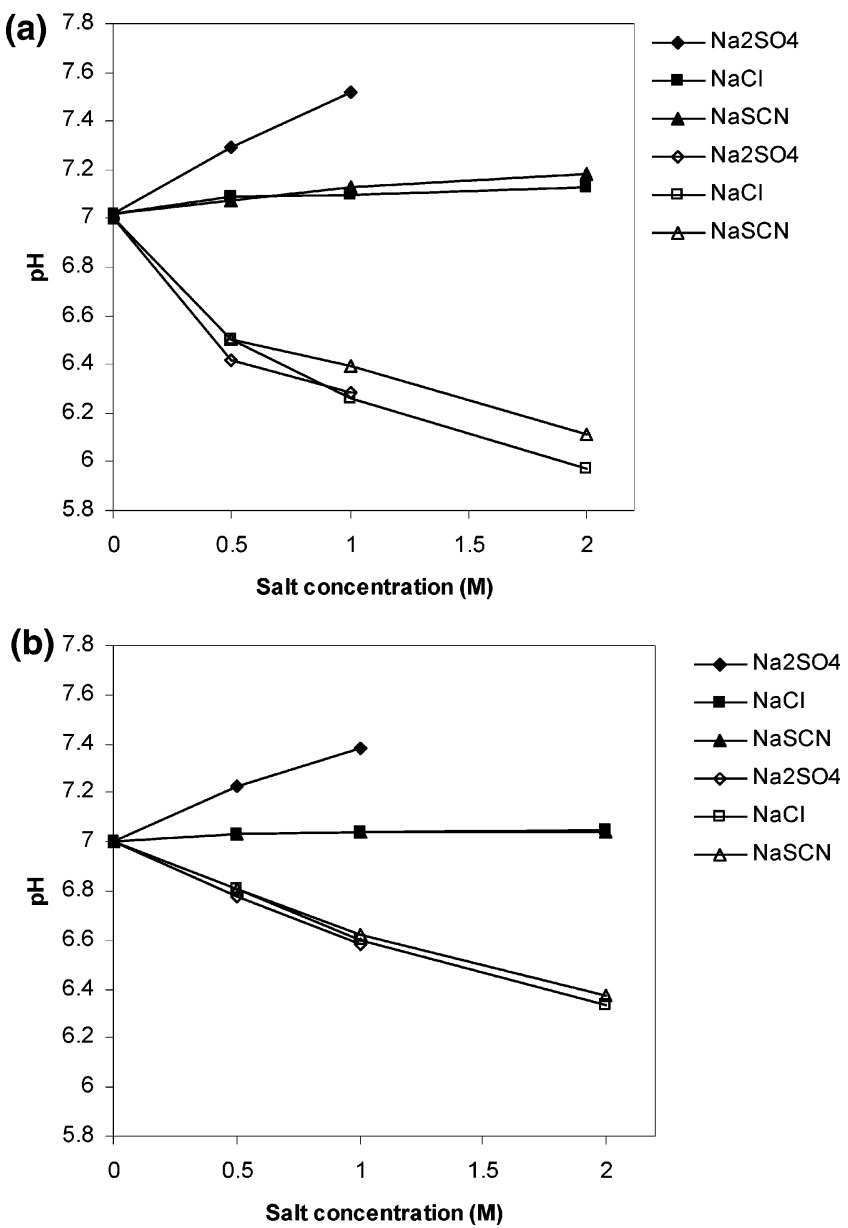

Figure 3. Measured $\mathrm{pH}$ of (a) 5 and (b) $200 \mathrm{mM}$ buffer solutions at initial $\mathrm{pH} 7$ with different concentrations of added salt. Closed symbols refer to Tris $\cdot \mathrm{HCl}$ buffer; open symbols refer to phosphate buffer.

ii. When high concentrations of salts are added to a buffer/ protein solution, the bulk $\mathrm{pH}$ is modified. With proteins the $\mathrm{pH}$ variation follows a direct or a reverse Hofmeister series depending on the $\mathrm{p} I .{ }^{9}$ Dispersion forces have been already used to rationalize these effects (section 4.3). ${ }^{49}$ This point is further complicated by the fact that the most commonly used technique for $\mathrm{pH}$ measurements, a $\mathrm{pH}$ meter equipped with a glass electrode, is likely to be affected by the presence of high concentrations of salts. Direct or reverse Hofmeister series can be obtained depending on the buffer. ${ }^{2}$ The result is that the measured $\mathrm{pH}$ likely differs from the real $\mathrm{pH}$ of the solution. The origin of this artifact is still unquantified since a full explanation of the phenomenon has not yet been given (section 4.3).

iii. On the basis of the structure of Candida rugosa lipase (section 4.4), new insights about the effects caused by salt addition and $\mathrm{pH}$ changes on enzymatic activity are proposed. $\mathrm{pH}$ and salt addition affect amino acid residues both at the active site and on the exterior surface. A different charge of the catalytically involved amino acids and a structure distortion may occur. The balance between these two effects is likely to be responsible for the different activity trends measured with different enzymes (section 4.5).

4.2 Failure of Conventional Kinetic Models To Explain the Effect of pH and Ionic Strength on Enzymatic Activity. Enzymes are affected by $\mathrm{pH}$. This is due to a combination of factors: (i) the binding of the substrate to the enzyme; (ii) the catalytic activity of the enzyme; (iii) the substrate degree of ionization; (iv) the variation of the structure of the enzyme (usually assumed important only at extreme $\mathrm{pH}$ values). ${ }^{50}$ 

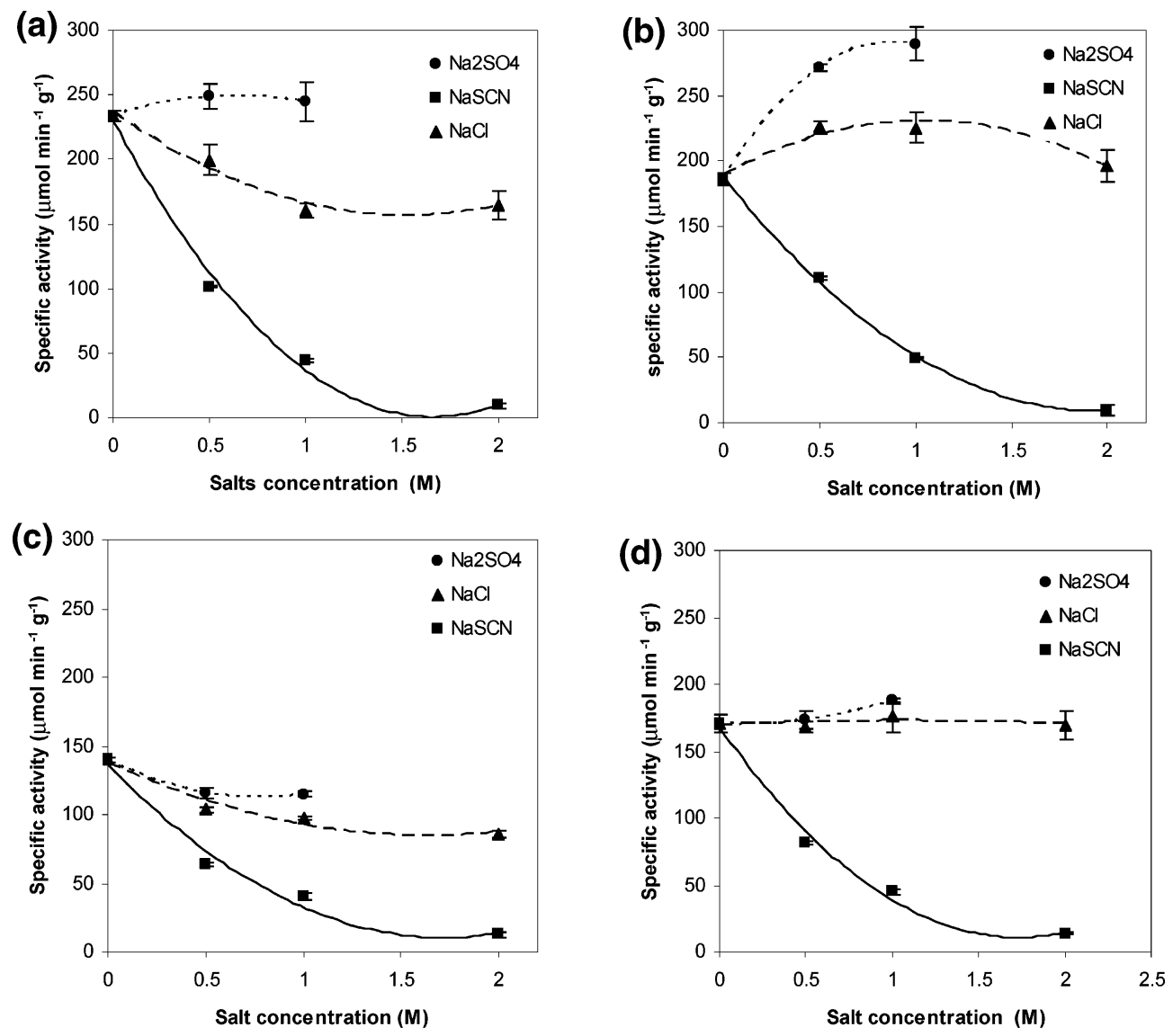

Figure 4. Enzymatic activity of Candida rugosa lipase versus salt concentration in different buffer solutions: (a) 5 mM sodium phosphate; (b) 200 mM sodium phosphate; (c) $5 \mathrm{mM}$ Tris $\cdot \mathrm{HCl}$; (d) $200 \mathrm{mM}$ Tris $\cdot \mathrm{HCl}$.

A simple model describing enzyme activity dependence on $\mathrm{pH}$ is the following:

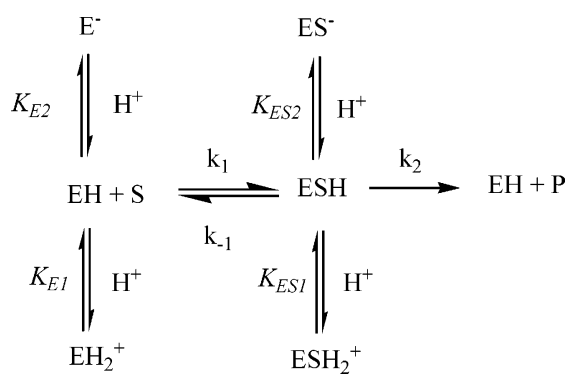

where $K_{\mathrm{E} 1}, K_{\mathrm{E} 2}, K_{\mathrm{ES} 1}$, and $K_{\mathrm{ES} 2}$ are the ionization constants of the ionizable amino acids (i.e., His and Glu) in the active site.

From this model a Michaelis/Menten-type relationship can be derived: ${ }^{50}$

$$
v=\frac{V_{\mathrm{MAX}^{\prime}[S]}}{K_{\mathrm{M}}{ }^{\prime}[S]}
$$

where

$$
V_{\mathrm{MAX}}{ }^{\prime}=\frac{V_{\mathrm{MAX}}}{\frac{\left[\mathrm{H}^{+}\right]}{K_{\mathrm{ES} 1}}+1+\frac{K_{\mathrm{ES} 2}}{\left[\mathrm{H}^{+}\right]}}
$$

$$
K_{\mathrm{M}}^{\prime}=K_{\mathrm{M}} \frac{\frac{\left[\mathrm{H}^{+}\right]}{K_{\mathrm{E} 1}}+1+\frac{K_{\mathrm{E} 2}}{\left[\mathrm{H}^{+}\right]}}{\frac{\left[\mathrm{H}^{+}\right]}{K_{\mathrm{ES} 1}}+1+\frac{K_{\mathrm{ES} 2}}{\left[\mathrm{H}^{+}\right]}}
$$

Kinetic parameters $K_{\mathrm{M}}$ and $V_{\mathrm{MAX}}$ are $\mathrm{pH}$ dependent. Nothing is supposed to be affected by the buffer used to obtain the desired $\mathrm{pH}$ value. Our results in Figures 1 and 2 clearly show the inadequacy of this model.

It has also been reported that ionic strength is an important parameter affecting enzyme activity. ${ }^{51}$ If the reaction rate depends upon the approach of charged moieties - as for the ratecontrolling step in the catalytic mechanism of chymotrypsin that involves the approach of two positively charged groups (His57 and Arg145)-increasing the ionic strength of the solution causes a significant increase/decrease in $k_{\text {cat }}{ }^{51}$ The approximate relationship below that is a consequence of classical electrolyte theory has been proposed:

$$
\log k=\log k_{0}+Z_{\mathrm{A}} Z_{\mathrm{B}} I^{1 / 2}
$$

Here $k$ is the measured rate constant, $k_{0}$ is the zero ionic strength rate constant, $Z_{\mathrm{A}}$ and $Z_{\mathrm{B}}$ are the electrostatic charges of the reacting species, and $I$ is the ionic strength of the solution. From this equation we can see that the reaction rate decreases when the charges are opposite in sign. It increases when the charges are identical. Again, results in Figure 4 show that the addition of monovalent salts $\mathrm{NaCl}$ and $\mathrm{NaSCN}$, which should cause the same ionic strength effect, leads instead to a very different enzymatic activity from that predicted. 
4.3. Effect of Salt Addition on pH of Proteins and Buffer Solutions: Dispersion Forces. It is an easy experiment to verify that the measured $\mathrm{pH}$ of a protein/buffer solution changes with the addition of strong electrolytes. Measured $\mathrm{pH}$ is ion specific and follows a Hofmeister series.

Some recent papers by Boström et al. ${ }^{9,40,49}$ predicted the behavior of some proteins in water solution in the presence of salts by taking into account both electrostatic and dispersion forces at the same level. They used the Poisson-Boltzmann cell model to calculate the net protein charge, surface $\mathrm{pH}$, solution $\mathrm{pH}$, and ion distributions.

The net protein charge, surface $\mathrm{pH}$, solution $\mathrm{pH}$, and ion distributions can be determined self-consistently via the nonlinear Poisson-Boltzmann equation for monovalent ions:

$$
\frac{\epsilon_{\mathrm{w}} \epsilon_{0}}{r^{2}} \frac{\mathrm{d}}{\mathrm{d} r}\left(r^{2} \frac{\mathrm{d} \phi}{\mathrm{d} r}\right)=-e\left[c_{+}(r)-c_{-}(r)+c_{\mathrm{H}^{+}}(r)\right]
$$

with the ion concentrations given by

$$
c_{ \pm}(r)=c \exp \left(-\left[ \pm e \phi+U_{ \pm}(r)\right] / k T\right)
$$

Here $\phi$ is the self-consistent electrostatic potential and $U_{ \pm}$is the interaction potential experienced by the ions. For the other symbols see the original papers., $9,40,49$

Some of the main results of these works are the following:

1. Two different quantities, bulk pH (minus the logarithm of the chemical potential) and surface $\mathrm{pH}$ (minus the logarithm of the electrochemical potential of a hydronium ion at the proteinsolution interface), do exist.

2. While chemical potential is constant, the electrochemical potential changes near interfaces. ${ }^{52}$ Surface $\mathrm{pH}$ is the quantity that influences the number of acid and basic charge groups on a surface. Bulk $\mathrm{pH}$ is in general quite different compared to surface $\mathrm{pH}$ near a protein surface.

3. The addition of small amounts of an anion having a high excess polarizability $\left(\mathrm{SCN}^{-}\right)$produces the same effect (in terms of $\mathrm{pH}$ variation) as higher amounts of an anion with a low excess of polarizability $\left(\mathrm{Cl}^{-}\right)$.

The difference between the bulk $\mathrm{pH}$ and the surface $\mathrm{pH}$ (or charge) of a protein depends on the anion present. In particular, highly polarizable anions, such as $\mathrm{SCN}^{-}$, are strongly attracted, because of dispersion forces, toward the protein surface. This leads to more hydronium ions near the surface, or more precisely, to a higher surface electrochemical potential, and more bound hydronium ions (higher charge).

Buffer and protein solutions behave similarly. Thus, for a buffer solution (e.g., phosphoric acid/phosphate) the fraction of neutral and negatively charged species depends on the $p K_{\mathrm{a}}$ values and on the bulk $\mathrm{pH}$. However, it depends also on the background salt solution via the "surface $\mathrm{pH}$ " or physicochemical environment near the buffer anion. Standard textbooks on $\mathrm{pH}$ in buffer and salt solutions never take into account any ion specificity (except a number of fitting parameters that should be different for each new situation).

As the salt concentration increases, the concentration of positively charged cations increases in the local region near the negatively charged phosphate ion. This leads by electrostatics to fewer hydronium ions bound to the phosphate ion and more in solution. Thus the bulk $\mathrm{pH}$ decreases with added salt. This effect is even more pronounced at high $\mathrm{pH}$ value, where a higher fraction of $\mathrm{HPO}_{4}{ }^{2-}$ is present and so more cations are attracted (and hence less hydronium ions). However, the $\mathrm{pH}$ decrease will also be different for different ion pairs. If $\mathrm{SCN}^{-}$and $\mathrm{Cl}^{-}$ ions are compared, the more polarizable $\mathrm{SCN}^{-}$anion experi- ences larger attractive ionic dispersion potentials toward the phosphate ion than does $\mathrm{Cl}^{-}$ion. Bulk $\mathrm{pH}$ should be higher in $\mathrm{NaSCN}$ solution than in a $\mathrm{NaCl}$ solution since there will be more anions near each phosphate ion with $\mathrm{SCN}^{-}$anions than with $\mathrm{Cl}^{-}$anions. This result is shown in Figure 3a only and for salt concentration higher than $1 \mathrm{M}$. By following this reasoning, one should expect that $\mathrm{SO}_{4}{ }^{2-}$ anions, because of their high charge and low excess polarizability, lead by electrostatics to a more pronounced $\mathrm{pH}$ decrease. This is not observed (Figure 3 ), as will be remarked below. In fact, for $200 \mathrm{mM}$ phosphate buffer no significant differences are found as a result of the different salt additions (Figure 3b).

Even in the presence of a cationic buffer, such as Tris $\cdot \mathrm{HCl}$, what is expected is that the effect of increasing the anion excess polarizability is usually to increase the bulk $\mathrm{pH}$. These trends (both the main electrostatic part and the ion-specific part) are in general agreement with our measurements with $\mathrm{Cl}^{-}$and $\mathrm{SCN}^{-}$. However, it is remarkable that the less polarizable (but with two net charges) $\mathrm{SO}_{4}{ }^{2-}$ anion gives the highest $\mathrm{pH}$ increases.

In order to explain results obtained with $\mathrm{Na}_{2} \mathrm{SO}_{4}$, we should reemphasize that the interpretation of the experimental measurement of $\mathrm{pH}$ is an open question. A recent work showed that the potential calibrated, measured, and interpreted as $\mathrm{pH}$ via conventional theory is clearly not the real $\mathrm{pH}^{2}$ It can vary from buffer to buffer depending on competition for the glass electrode surface by buffer anion and salt type. Here we do not consider further this complication since it is still open.

4.4. Structure of the Lipase from Candida rugosa. In order to rationalize our results, we recall what is known about the structure and the active site of Candida rugosa lipase. With this in mind we can then see how competing dispersion or NES forces acting on ions can accommodate the specific effect of different anions on the measured enzymatic activity.

The lipase from Candida rugosa (CRL) comprises 534 amino acids with $M_{\mathrm{r}}$ of approximately $60 \mathrm{kDa}$. CRL is a single-domain molecule and belongs to the family of $\alpha / \beta$ hydrolase fold proteins. The enzyme shows about a $40 \%$ amino acid sequence identical to Geotricum candidum lipase and about $25 \%$ equivalent to acetylcholinesterase. Conserved residues include the catalytic triad, disulfide forming cysteines, and some salt bridges. The active site is constituted by the amino acids Ser209, His449, and Glu341. ${ }^{53}$ This site is buried from the solvent by a single surface loop (flap). The structure of this enzyme has been resolved in two conformations: one where the flap occludes the active site from the solvent (closed form) $;{ }^{54}$ the other where the active site is fully available to the solvent (open form). ${ }^{53}$

The loop has an elongated shape and lies flat on the protein surface above the active site. It encompasses a distorted helical turn and a $\alpha$-helix, and has an amphipatic character. It is hydrophobic on the side facing the protein and interacts with the hydrophobic residues surrounding the active site. On the upper side, exposed to the solvent, it is hydrophilic. ${ }^{54}$ Besides the catalytic triad, as will be explained below, the oxyanion hole also has a fundamental role in the catalysis, since it stabilizes the transition state. This is formed by the NH groups of Ala210 and Gly124. ${ }^{53}$

4.5. New Insights on Specific Anion Effects on Enzymatic Activity. At the active site of CRL three amino acid residues are involved in the catalytic mechanism. The Ser209 residue is neutral whereas the other two residues are charged; in particular, His449 ( $K_{\mathrm{a}}$ 6.04) is cationic and Glu341 ( $K_{\mathrm{a}}$ 4.07) anionic. In the first step of the catalytic path, the lone pair of the :OH group from Ser209 attacks the ester bond of the $p$-NPA to form 

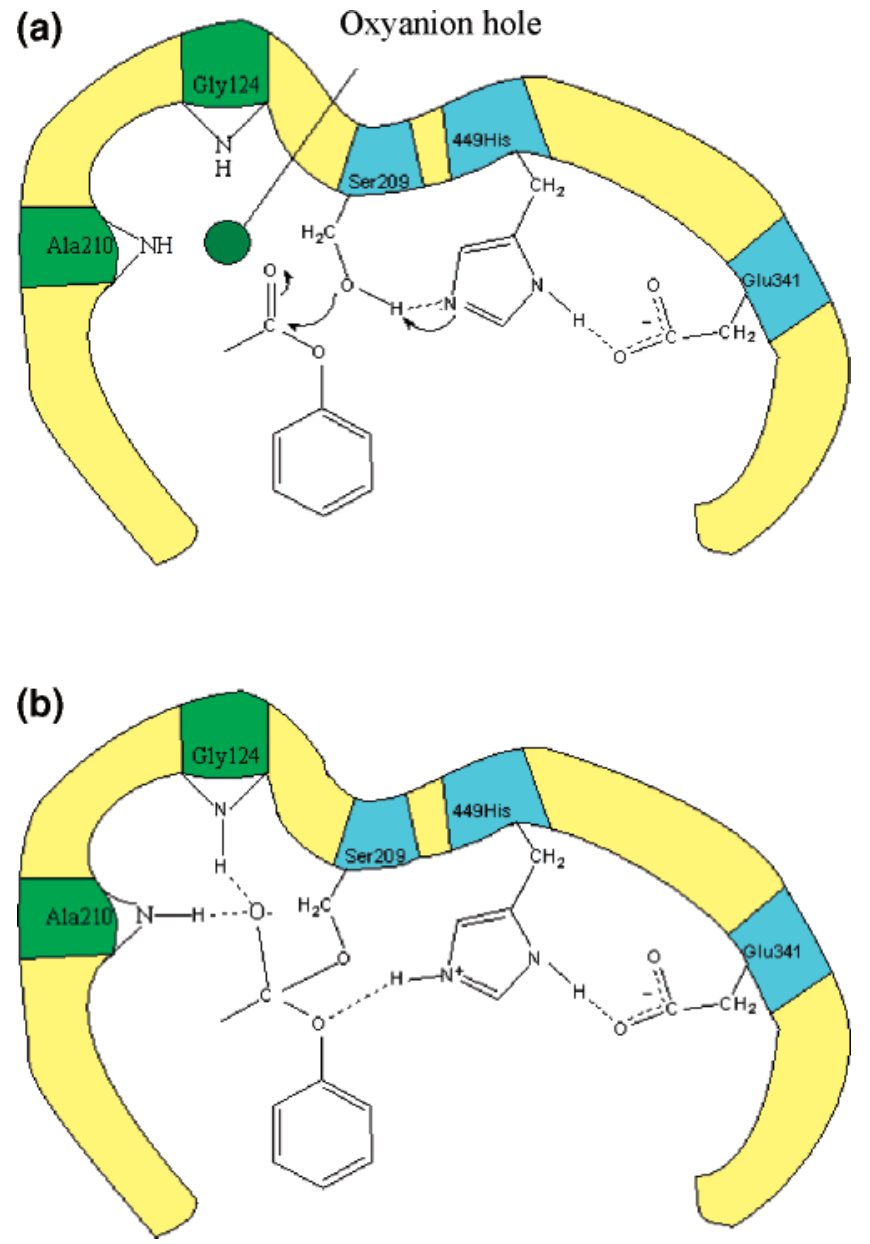

Figure 5. Schematic representation of the active site of Candida rugosa lipase. (a) Binding of the substrate ( $p$-nitrophenyl acetate) by Ser209 with the assistance of Glu341 and His449. (b) Formation of the tetrahedral intermediate and stabilization of the oxyanion.

a tetrahedral intermediate. This electron pair is readily available because of the presence of the Glu341 and the His449 residues (Figure 5a). A tetrahedral intermediate with an oxyanion is formed; this last is located in the "oxyanion hole". It is stabilized by the formation of two hydrogen bonds with the NH groups of Ala210 and Gly124 (Figure 5b).

The catalytic activity is strongly affected by surface $\mathrm{pH}$ (which determines the ionization state of the amino acids) of the active site. The mechanism is inhibited when both residues Glu341 and His449 are protonated, and cannot then assist the oxygen of Ser209 in its nucleophilic attack on the carbonyl carbon of the ester. This prevents the formation of the tetrahedral intermediate that involves His449 (proton transfer from Ser209) and Glu341 for the delocalization of the charge.

On the basis of the theoretical results obtained by Boström et al., ${ }^{40,49}$ the presence of a strongly polarizable $\mathrm{SCN}^{-}$anion at high concentrations should lead to a higher amount of hydronium ions bound to surface amino acid residues. When the Candida rugosa lipase is in its active conformation, the active site is fully available to the solvent, ${ }^{53}$ so adsorption of $\mathrm{SCN}^{-}$is possible and is likely to occur. This should lead to the protonation of His449 and Glu341 that can no longer assist the Ser209 in the nucleophilic attack of the carbonyl group of the $p$-NPA.

In general, protonation of His residues corresponds to the already observed ${ }^{55}$ apparent $\mathrm{p} K_{\mathrm{a}}$ shift that was supposed to be anion specific. Taking into account the effects of dispersion forces on $\mathrm{p} K_{\mathrm{a}}$, theoretical calculations of His residues have already been shown to account for the mechanism at the origin of the observed effect. ${ }^{56}$

Besides this effect, an additional phenomenon might be responsible for the dramatic decrease in enzymatic activity observed with $\mathrm{SCN}^{-}$anions. The native conformation of an enzyme is determined by a complex interplay of many-body molecular forces subsumed under names such as ionic, hydrogen bond, many-body dipolar, and dipole-induced dipole and van der Waals interactions. These forces provide stability to the enzyme under physiological conditions and prevent deleterious conformational changes that could cause deactivation. It is likely that $\mathrm{SCN}^{-}$adsorption is able to interfere with the hydration of groups involved in these interactions at the enzyme surface level even at the active site. This could cause a distortion of the active site, i.e., of the amino acids of the catalytic triad and those forming the oxyanion hole. This distortion should modify the cavity and so render the stabilization of the transition state impossible. This effect, if confirmed, should lead to the dramatic diminution of enzymatic activity as shown in Figure 4.

The destruction of enzyme structure caused by chaotropic anions is an explanation commonly given to justify enzyme inactivation. ${ }^{12}$ What is new here is that the direct effect of anions can be traced to the anionic adsorption driven by the manybody dispersion forces rather than an effect mediated by bulk water structure. ${ }^{44-46}$

On the other (kosmotropic) side of the Hofmeister series the low polarizability of the anion $\mathrm{SO}_{4}{ }^{2-}$ implies that it interacts mainly via electrostatics alone. The activating-deactivating phenomena depend on the solution buffer. In this case the effect on the activity caused by $\mathrm{SO}_{4}{ }^{2-}$ addition is likely to be related, at least at a first approximation, to the bulk $\mathrm{pH}$ shift. This is true, for example, for $200 \mathrm{mM}$ phosphate buffer where the addition of $1 \mathrm{M} \mathrm{Na}_{2} \mathrm{SO}_{4}$ gives a $\mathrm{pH}$ shift from 7.00 to 6.62 (see Figure 3b) and an enzymatic activity of $289 \mu \mathrm{mol} \mathrm{min}{ }^{-1} \mathrm{~g}^{-1}$ (Figure $4 b$ ). This $\mathrm{pH}$ shift goes in the direction of the maximum in the activity vs $\mathrm{pH}$ curve $(\mathrm{pH} 6.52$; enzymatic activity $=268$ $\mu \mathrm{mol} \min ^{-1} \mathrm{~g}^{-1}$ ) in Figure $1 \mathrm{~b}$.

In the case of $200 \mathrm{mM}$ Tris $\cdot \mathrm{HCl}$ the addition of $1 \mathrm{M} \mathrm{Na}_{2} \mathrm{SO}_{4}$ gives a $\mathrm{pH}$ shift from 7.00 to 7.38 (Figure $3 \mathrm{~b}$ ) and an enzymatic activity of $188 \mu \mathrm{mol} \mathrm{min}{ }^{-1} \mathrm{~g}^{-1}$ (Figure 4d). If this $\mathrm{pH}$ shift in the activity vs $\mathrm{pH}$ curve is considered (Figure $1 \mathrm{~b}$ ), an enzymatic

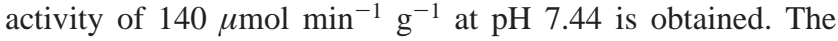
different effects of sulfate anion (activation/deactivation) observed with the different buffers confirms the importance of the choice of weak electrolytes used to set the bulk $\mathrm{pH}$. The choice of buffer is supposed not to be influential, but clearly it is.

If these explanations are correct, the effect induced by the HS neutral anion $\mathrm{Cl}^{-}$is partially due to a combination of nonspecific electrostatic forces and ion-specific NES forces. This is also tuned by the solution buffer, with competition for the active site between chloride and buffer ions being explicit. That this is probably so receives support from the observation that the effect of high buffer concentration $(200 \mathrm{mM})$ is also explainable in terms of Hofmeister series. Indeed, when buffer concentration is low $(5 \mathrm{mM})$, its weak buffering capacity does not allow reaching a single maximum. It is however remarkable that the three buffers produce similar maximal activities although at different $\mathrm{pH}$ values (see Figure 1a). When buffer concentration increases, the higher buffering capacity allows reaching the real value of optimal $\mathrm{pH}$ (around 6.5). At this point a Hofmeister effect appears, giving different activities, namely a high value for the kosmotropic phosphate and citrate anionic 
buffers and a low value for the chaotropic Tris $\cdot \mathrm{HCl}$ cationic buffer (see Figure 1b).

\section{Conclusions}

The present work demonstrates explicitly the specific effects of weak and strong electrolytes on enzymatic activity of a lipase. Previously the consensus has been that the former acts only as buffers, i.e., to set $\mathrm{pH}$ only, and that the latter acts as ionic strength regulators, i.e., to modify electrostatic forces of association only. Here we have shown that this picture is too simple. Both buffers and salt anions have specific effects that fall within the ambit of the Hofmeister series phenomena. This is not a trivial phenomenon. It is one that conventional biochemistry textbooks have neglected even though Hofmeister effects have been known for more than 100 years and were first demonstrated with protein solubility. The reason is evidently due to the circumstance that the underlying theories of physical chemistry have not been fully satisfactory and predictive. They are mainly limiting laws valid only for dilute solutions.

Recently some of the flaws in classical theories have been exposed..$^{38}$ Incorporation of many-body NES forces into theories is providing new insights into Hofmeister phenomena. These insights can be used to rationalize several phenomena both in biochemistry and in colloidal chemistry problems. ${ }^{57,58}$

Acknowledgment. MIUR and CSGI are thanked for support. D.B. thanks the Erasmus Project for her scholarship.

\section{References and Notes}

(1) Kunz, W.; Nostro, P. L.; Ninham, B. W. Curr. Opin. Colloid Interface Sci. 2004, 9, 1.

(2) Salis, A.; Pinna, M. C.; Bilaničová, D.; Monduzzi, M.; Lo Nostro, P.; Ninham, B. W. J. Phys. Chem. B 2006, 110, 2949.

(3) Robinson, R. A.; Stokes, R. H. Electrolyte Solutions; Butterworths: London, 1959.

(4) Hofmeister, F. Arch. Exp. Pathol. Pharmakol. 1888, 24, 247

(5) Kunz, W.; Henle, J.; Ninham, B. W. Curr. Opin. Colloid Interface Sci. 2004, 9, 19.

(6) Loeb, J. Science 1920, 52, 449

(7) Gustavson, K. H. Specific ion effects in the behaviour of tanning agents toward collagen treated with neutral salts. In Colloid Symposium Monograph; Weiser, H. B., Ed.; The Chemical Catalog Company Inc.: New York, 1926.

(8) Riés-Kautt, M. M.; Ducruix, A. F. J. Biol. Chem. 1989, 264, 745

(9) Boström, M.; Tavares, F. W.; Finet, S.; Skouri-Panet, F.; Tardieu,

A.; Ninham, B. W. Biophys. Chem. 2005, 117, 217.

(10) Carbonnaux, C.; Riés-Kautt, M. M.; Ducruix, A. F. Protein Sci. 1995, 5, 2123

(11) Warren, J. C.; Cheatum, S. G. Biochemistry 1966, 5, 1702

(12) Warren, J. C.; Stowring, L.; Morales, M. F. J. Biol. Chem. 1966, $241,309$.

(13) Wondrak, E. M.; Louis, J. M.; Oroszlan, S. FEBS Lett. 1991, 280, 344

(14) Park, C.; Raines, R. T. J. Am. Chem. Soc. 2001, 123, 11472.

(15) Kim, H.-K.; Tuite, E.; Nordén, B.; Ninham, B. W. Eur. Phys. J. E 2001, 4, 411 .

(16) Wright, D. B.; Banks, D. D.; Lohman, J. R.; Hilsenbeck, J. L.; Gloss, L. M. J. Mol. Biol. 2002, 323, 327.

(17) Ramos, C. H. I.; Baldwin, R. L. Protein Sci. 2002, 11, 1771
(18) Terland, O.; Flatmark, T. Biochem. J. 2003, 369, 675.

(19) Zoldàk, G.; Sprinzl, M.; Sedlàk, E. Eur. J. Biochem. 2004, 271

(20) Pinna, M. C.; Salis, A.; Monduzzi, M.; Ninham, B. W. J. Phys Chem. B 2005, 109, 5406.

(21) Pinna, M. C.; Bauduin, P.; Touraud, D.; Monduzzi, M.; Ninham,

B. W.; Kunz, W. J. Phys. Chem. B 2005, 109, 16511.

(22) Low, P. S.; Somero, G. N. Proc. Natl. Acad. Sci. U.S.A. 1975, 72 , 3305 .

(23) Pahlich, E.; Gelleri, B.; Kindt, R. Planta 1978, 138, 161.

(24) Craine, J. E.; Daniels, G. H.; Kaufman, S. J. Biol. Chem. 1973, 248,7838

(25) Kunz, W.; Belloni, L.; Bernard, O.; Ninham, B. W. J. Phys. Chem. B 2004, 108, 2398 .

(26) Maheshwari, R.; Sreeram, K. J.; Dhathathreyan, A. Chem. Phys. Lett. 2003, 375, 157-161.

(27) Gurau, M. C.; Lim, S.-M.; Castellana, E. T.; Albertorio, F.; Kataoka, S.; Cremer, P. S. J. Am. Chem. Soc. 2004, 126, 10522.

(28) Lo Nostro, P.; Fratoni, L.; Ninham, B. W.; Baglioni, P. Biomacromolecules $\mathbf{2 0 0 2}, 3,1217$

(29) Lo Nostro, P.; Lopes, J. R.; Ninham, B. W.; Baglioni, P. J. Phys. Chem. B 2002, 106, 2166.

(30) Lo Nostro, P.; Ninham, B. W.; Ambrosi, M.; Fratoni, L.; Palma S.; Allemandi, D.; Baglioni, P. Langmuir 2003, 19, 9583.

(31) Lonetti, B.; Lo Nostro, P.; Ninham, B. W.; Baglioni, P. Langmuir $\mathbf{2 0 0 5}, 21,2242$

(32) Washabaugh, M. W.; Collins, K. D. J. Biol. Chem. 1986, 261, 12477

(33) Collins, K. D. Q. Rev. Biophys. 1985, 18, 323.

(34) Collins, K. D. Proc. Natl. Acad. Sci. U.S.A. 1995, 92, 5553.

(35) Collins, K. D. Biophys. J. 1997, 72, 65.

(36) Hribar, B.; Southall, N. T.; Vlachy, V.; Dill, K. A. J. Am. Chem. Soc. 2002, 124, 12302 .

(37) Ninham, B. W. Adv. Colloid Interface Sci. 1999, 1, 1.

(38) Ninham, B. W.; Yaminsky, V. Langmuir 1997, 13, 2097.

(39) Boström, M.; Williams, D. R. M.; Ninham, B. W. Phys. Rev. Lett. 2001, 87, 8103 .

(40) Boström, M.; Williams, D. R. M.; Ninham, B. W. Curr. Opin. Colloid Interface Sci. 2004, 9, 48.

(41) Boström, M.; Ninham, B. W. Langmuir 2004, 20, 7569.

(42) Boström, M.; Ninham, B. W. Biophys. Chem. 2005, 114, 95.

(43) Boström, M.; Ninham, B. W. J. Phys. Chem. B 2004, 108, 12593.

(44) Omta, A. W.; Kropman, M. F.; Woutersen, S. J. Chem. Phys. 2003

$119,12457$.

(45) Omta, A. W.; Kropman, M. F.; Woutersen, S.; Bakker, H. J. Science 2004, 301, 347 .

(46) Zhang, Y.; Furyk, S.; Bergbreiter, D. E.; Cremer, P. S. J. Am. Chem Soc. 2005, 127, 14505 .

(47) Good, N. E.; Winget, G. D.; Winter, W.; Connolly, T. N.; Izawa, S.; Singh, R. M. M. Biochemistry 1966, 5, 467.

(48) Voinescu, A. E.; Bauduin, P.; Pinna, M. C.; Touraud, D.; Ninham,

B. W.; Kunz, W. J. Phys. Chem. B 2006, 110, 8870.

(49) Boström, M.; Ninham, B. Colloids Surf., A: Physicochem. Eng. Aspects 2006, 291, 24.

(50) Voet, D.; Voet, J. G. Biochemistry; Wiley: New York, 1990

(51) Chaplin, M.; Bucke, C. Effect of pH and ionic strength. In Enzyme Technology; Cambridge University Press: New York, 1990.

(52) Goldstein, L.; Levin, Y.; Katchalski, E. Biochemistry 1964, 3, 1913.

(53) Grochulski, P.; Li, Y.; Schrag, J. D.; Bouthillier, F.; Smith, P.; Harrison, D.; Rubin, B.; Cygler, M. J. Biol. Chem. 1993, 268, 12843.

(54) Grochulski, P.; Li, Y.; Schrag, J. D.; Cygler, M. Protein Sci. 1994 3,82 .

(55) Lee, K. K.; Fitch, C. A.; Lecomte, J. T. J.; Carcia-Moreno, E. B. Biochemistry 2002, 41, 5656.

(56) Boström, M.; Williams, D. R.; Ninham, B. W. Biophys. J. 2003 85,686 .

(57) Ninham, B. W.; Boström, M. Cell. Mol. Biol. 2005, 51, 803.

(58) Ninham, B. W. Prog. Colloid Polym. Sci. 2002, 120, 1. 